\title{
A Systematic Observation of Coach Leadership Behaviours in Youth Sport
}

\author{
Jordan Sylvain Lefebvre, Jennifer Turnnidge \& Jean Côté
}

To cite this article: Jordan Sylvain Lefebvre, Jennifer Turnnidge \& Jean Côté (2019): A Systematic Observation of Coach Leadership Behaviours in Youth Sport, Journal of Applied Sport Psychology, DOI: $10.1080 / 10413200.2019 .1609620$

To link to this article: https://doi.org/10.1080/10413200.2019.1609620

Accepted author version posted online: 25 Apr 2019.

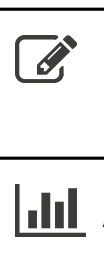

Submit your article to this journal $\asymp$

لll Article views: 53

View Crossmark data ¿ 
Resubmitting to the Journal of Applied Sport Psychology

Pages: 18; Tables: 2; Figures: 1

Keywords: Coaching; Leadership; Youth Sport

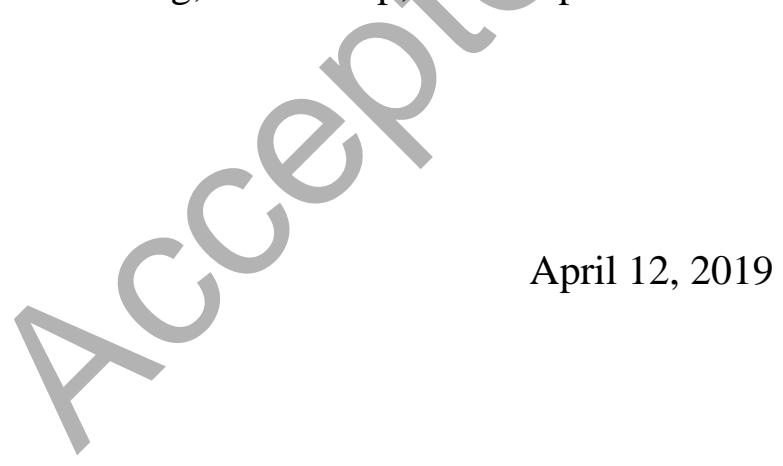




\begin{abstract}
The purpose of this study was to examine coach leadership behaviours within the fullrange leadership model using systematic observation. Seven male head coaches of youth soccer teams were observed over two training sessions and one competition, resulting in 9,760 recorded behaviours. Descriptive data revealed that the majority of coach behaviours in training and competition were neutral interactive behaviours. When displaying leadership (e.g., transformational, transactional), coaches more frequently displayed individualized consideration, inspirational motivation, and less frequently, intellectual stimulation, and idealized influence. These findings provide insight into the leadership behaviours employed by coaches, which can inform future leadership workshops focused on promoting athlete development.
\end{abstract}

Keywords: Coaching; Leadership; Youth Sport

Word Count: 102/100 
A Systematic Observation of Coach Leadership Behaviours in Youth Sport

In recent years, the full-range leadership model (Bass \& Riggio, 2006) has been a common framework utilized by researchers to investigate how coaches' leadership behaviours are associated with favourable outcomes in youth sport (e.g., Tucker, Turner, Barling, \& McEvoy, 2010; Vella, Oades, \& Crowe, 2013). Originating from organizational psychology, the full-range leadership model consists of three core leadership styles: laissez-faire, transactional, and Transformational Leadership (TFL). Starting with the least active approach, laissez-faire leadership —also termed non-leadership—characterizes leaders who operate with indifference toward followers and often delay or omit their responsibilities (Bass \& Riggio, 1994). For instance, laissez-faire leaders might avoid decision making, withhold feedback, or ignore followers' requests for help. As a more active approach, transactional leaders exhibit behaviours characterized as contingent rewards and management by exception (active and passive). In other words, transactional leaders use rewards, punishment, and positive feedback to acknowledge and influence followers' performances. Although transactional leadership has been demonstrated to be an effective leadership style, popular contentions argue that transactional alone is insufficient to extract the full potential of followers. If fact, TFL is known to augment any effects generated by transactional behaviours (Bass \& Riggio, 2006).

According to Bass and Riggio (2006), TFL is characterized by four separate dimensions. The first dimension, idealized influence, is when leaders foster trust and respect by modelling prosocial behaviours. Second, inspirational motivation is when leaders convey a compelling vision and express high expectations. Third, intellectual stimulation is when leaders encourage followers to engage in issues from multiple perspectives and question internally held assumptions. Lastly, individualized consideration is when leaders celebrate the successes of their 
followers and demonstrate a genuine sense of care and concern towards individuals. The application of coach TFL has been advocated for the youth sport setting because a central tenet of TFL theory is to enable followers to reach their full potential and to transform followers into future leaders (Bass \& Riggio, 2006). Further, it emphasizes quality relationships and promotes athletes' developmental experiences by focusing not just on performance, but also on the growth and personal development of followers (Turnnidge \& Côté, 2018; Vella et al., 2013).

A handful of studies have investigated the impact of TFL in youth sport, revealing coach transformational leadership to be associated with numerous developmental outcomes, such as perceived competence, cohesion/relatedness (Stenling \& Tafvelin, 2014), pro-social behaviours (Tucker et al., 2010), and positive developmental experiences (Vella et al., 2013). For instance, Tucker et al. (2010) conducted a season-long longitudinal study investigating the impact of coaches' leadership behaviours on the on-ice aggression of 183 youth recreational ice-hockey players. Surveys were administered to players, parents, and coaches at two time points (i.e., beginning and end of season). Mediation analyses revealed that TFL was negatively associated with on-ice aggression (i.e., anti-social behaviours). Moreover, in their cross-sectional investigation of TFL, Vella et al. (2013) employed a series of questionnaires to investigate the relation between TFL and positive developmental experiences in 455 youth recreational soccer players. Linear regressions revealed that youth athletes' perceptions of coaches' TFL behaviours significantly predicted an overall measure of positive developmental experiences (i.e., developmental assets, such as personal/social skills, cognitive skills, initiative, goal setting, and negative experiences). More specifically, these positive developmental experiences were best predicted when athletes reported an elevated degree of perceived individualized consideration, intellectual stimulation, and coach role modeling behaviours (i.e., idealized influence). 
Collectively, these findings lend support to the notion that coaches' TFL behaviours can influence youth's developmental outcomes in youth sport.

Despite preliminary support for TFL in youth sport, there are limitations regarding the methodological approach utilized by researchers in this context. First, studies that assess TFL in sport (e.g., Tucker et al., 2010; Vella et al., 2013) commonly explore the correlational/causal mechanisms of TFL. However, Potrac, Brewer, Jones, Armour, and Hoff (2000) argue that to understand micro-level interactions (e.g., coach and athlete), it is necessary to generate baseline descriptive data of coach behaviours prior to conducting inductive analytical techniques. Second, TFL in youth sport is typically assessed through self-report questionnaires based on either coach perceptions of their own behaviours or athlete perceptions of their coach's behaviours (Arthur, Bastardoz, \& Eklund, 2017). Relying on only one method of measurement (e.g., self-report) is problematic and can result in a common-source, common-method variance bias, which stipulates that outcome variance is attributable to the method of measurement as opposed to the construct (e.g., leadership; Arthur et al., 2017). To address these limitations, many researchers have advocated for the use of observational methods (Potrac et al., 2000). Although a number of reputable observation tools have been developed to measure coach behaviours, such as the Coach Behaviour Assessment System, the Arizona State University Observation System, and the Coach-Athlete Interaction Coding System (see Vierimaa, Turnnidge, Evans, and Côté, 2016), these instruments tend to rely on the professional knowledge of coaching (e.g., providing instruction, technical feedback). However, according to Turnnidge and Côté (2019) coaches' behavioural manifestations of professional knowledge do not necessarily represent the full range of effective coach behaviours. Notably, Turnnidge and Côté (2019) have developed a novel 
observational instrument that is specifically designed to capture coaches' full-range leadership behaviours in sport.

The purpose of this study was to explore the leadership behaviours of youth sport coaches using observational methodology. Specifically, the aim was to contrast quantitative descriptions of coach behaviours across the full-spectrum of leadership, with a particular focus on TFL behaviours. This was accomplished by using Turnnidge and Côté's (2019) Coach Leadership Observation System (CLAS) to code the frequency of coach leadership behaviours.

\section{Methods}

\section{Participants}

The participants came from seven competitive youth soccer teams, recruited through a competitive soccer club in Eastern Ontario, Canada. Thirteen coaches of various age levels were initially contacted, of which, eight male coaches agreed to participate. One coach became ineligible to continue during the data collection due to a mid-season coaching change. Four coached female teams: Under 13 (U13), U14, U15 and U16; and three coached male teams: U13, $\mathrm{U} 16(\mathrm{a})$, and $\mathrm{U} 16(\mathrm{~b})$. The coaches ranged from 40 to 50 years of age $(M=44.29, S D=3.35)$, with two to eight years of previous soccer coaching experience $(M=7.71, S D=4.68)$. There were 73 athletes (40 female), ranging from 12 to 16 years of age $(M=14.26, S D=1.27)$. The number of seasons athletes formerly spent with their current head coach ranged from one to eight seasons $(M=2.26, S D=1.72)$. All the coaches acquired the minimum coaching qualifications required by the soccer organization and none of the coaches reported having any type of formalized leadership training. 


\section{The Coach Leadership Assessment System}

The coaches' leadership behaviours were measured through systematic observation using the CLAS (Turnnidge \& Côté, 2019), an exhaustive and exclusive systematic observation coding system designed to code coach leadership. Accordingly, coach behaviours are coded within one of 17 lower-order behaviour dimensions, which are further classified into one of eight higherorder dimensions (see Table 1). The first six higher-order dimensions represent the full-range of leadership: (1) idealized influence (two dimensions), (2) inspirational motivation (four dimensions), (3) intellectual stimulation (three dimensions), (4) individualized consideration (two dimensions), (5) transactional (two dimensions), and (6) laissez-faire (one dimension). The CLAS also includes two higher-order dimensions to address a range of behaviours that were left unaccounted for during the development of the observation instrument: (7) neutral (two dimensions), and (8) toxic (two dimensions). Notably, the neutral dimension is characterized as either silent observation or interactive behaviours that do not align with a leadership dimension (e.g., instructing an athlete on positioning). That is, a given behaviour is coded as neutral only if it does not fit within the full-range spectrum of behaviours (e.g., the coach does not provide expectations or a rational for their instruction; see Table 1 for example behaviour codes for each higher-order leadership dimension). Finally, while developing the CLAS, several strategies were employed to establish initial measures of face validity (see Turnnidge \& Côté, 2019). Further, Turnnidge and Côté (2019) assessed the inter-rater reliability (range $=78-84 \%$, kappa range $=$ $.75-.82$ ), and intra-rater reliability (range $=75-76 \%$, kappa range $=.72-.75$ ) of the CLAS across four coders, thus providing evidence for the instrument's reliability. 


\section{Procedure}

After obtaining approval from the general research ethics board, the primary researcher met with athletes, parents, and coaches to introduce the study and distribute letters of information and consent forms. Each team was video recorded three times: two training sessions and one competition. The purpose of videotaping the first training session was to acclimate the athletes and coaches to the presence of the camera and researchers. The subsequent observations were used for data analysis. During each observation session, two different video cameras were used to capture different angles, each paired with a microphone to capture coach and athlete verbalizations. The videotaping began upon the arrival of the first athlete and finished following the final team huddle as the athletes dispersed upon termination of the training and/or competition. An effort was made to remain consistent across all video-recording sessions $\left(M_{\text {training }}=1: 25: 00 ; M_{\text {competition }}=1: 53: 29\right)$.

The video-footage of both cameras were synchronized and paired, and then uploaded into Noldus observer XT software (V.9). The observational data was then continuously coded using the CLAS. The primary and secondary coders underwent rigorous training in accordance with the coding protocol of the CLAS (see Erickson \& Côté, 2015; Turnnidge \& Côté, 2019). During coder training, the primary coder attained $75 \%$ inter-coder reliability with the developer of the coding system on two consecutive (i.e., x2) 10-minute video segments (range $=80-85 \%$, kappa range $=.73-.83$ ). Further, the primary and secondary coder (i.e., research assistant) were assessed for reliability prior to $(\mathrm{x} 2)$ and after $(\mathrm{x} 1)$ the coding process (range $=81-85 \%$, kappa range $=.73$ $.77)$. 


\section{Data Analysis}

A series of exploratory descriptive observations were conducted to examine the frequency of youth sport coaches' full-range leadership behaviours in training and competition. Given the exploratory and descriptive nature of the study, the analytical process was conducted through step-wise unpremeditated analyses. For instance, the first analysis provided an overall picture of coach leadership across training and competition, which produced findings that served to inform and direct subsequent analyses. At various occasions, paired-samples t-tests were conducted to provide further assessment. The t-tests were employed intermittently to avoid conducting an excessive number of unwarranted inferential analyses. Due to the lack of power and generalizability of the current sample, these t-tests were conducted solely for descriptive purposes and should therefore be interpreted with caution. Notably, due to the variation in the duration of video sessions, frequency is represented by proportional frequency (i.e., percentage of leadership) for each variable. For instance, the frequency of idealized influence was calculated using the following formula: idealized influence behaviours/total coach behaviours*100.

\section{Results}

A total of 9,760 leadership and neutral behaviours were coded across seven training sessions (4,906 behaviours) and seven competitions (4,854 behaviours). Table 2 displays the frequency of all higher-order leadership and neutral behaviour dimensions. Importantly, the findings suggest that approximately $75 \%$ of coach behaviours were neutral. Of these neutral behaviours, coaches engaged in silent observation for $28.2 \%$ of their behaviours in training and $35.2 \%$ in competition. More notably, $47 \%$ of behaviours in training and $42.3 \%$ of behaviours in competition were neutral interactive (i.e., did not have a discernable leadership tone).

Accordingly, the neutral dimension, and in particular the neutral interactive behaviours, appear 
to be overwhelmingly more prevalent in contrast to coach leadership behaviours. The remainder of the results will focus on the frequencies of the leadership-specific higher-order dimensions across playing contexts through a series of descriptive exploratory analyses, to explore the $25 \%$ of coach behaviours that were coded as demonstrating leadership within the full-range.

First, the frequencies for the higher-order leadership dimensions across playing context are presented in Figure 1a. Figure 1a illustrates that the pattern of frequency for the leadership dimensions are very similar across both training and competition, suggesting that coaches display comparable leadership behaviours across playing contexts. To further explore these similarities, the seven leadership dimensions were merged together to form an average leadership score. This was done to contrast training and competition-irrespective of individual leadership dimensions. Figure 1b displays the mean frequency of leadership in training and competition. This figure supports the speculation that coaches display similar frequencies of leadership behaviours across playing contexts. To provide further support, a paired-samples t-test was conducted to contrast the frequency of leadership across the two playing contexts. The results indicated that coaches display comparable frequencies of leadership behaviours in training $(M=$ $3.54 \%, S E=0.19)$, compared to competition $(M=3.22 \%, S E=0.21), t(6)=1.06, p=.332$.

Second, given the similarities in leadership across playing contexts, leadership behaviours in training and competition were merged together in the next phase to contrast the leadership dimensions - irrespective of playing context. This allowed for greater insight into the specific dimensions of leadership exhibited by coaches. Figure 1c provides the average frequency for each higher-order leadership dimension. Focusing on the four components of TFL, the findings in Figure 1c suggest that individualized consideration, followed by inspirational motivation were the most frequently displayed leadership dimensions by coaches, and thus, the 
most frequently displayed components of TFL. Conversely, intellectual stimulation, followed by idealized influence were the least frequently displayed components of TFL. Next, the frequency of transactional leadership appears to be comparable with the lower levels of the TFL components. Finally, the laissez-faire and toxic leadership dimensions equally emerged as the least frequently displayed leadership dimensions.

Third, in order to provide further support for these descriptive observations, and provided that exploring the four components of TFL is a major focus of the study, six paired-samples ttests were conducted using Bonferroni adjusted alpha levels of .008 to contrast the components of TFL. The findings are presented in descending order of frequency. Results indicate that coaches displayed similar levels of individualized consideration $(M=9.29 \%, S E=1.04)$ and inspirational motivation $(M=6.68 \%, S E=0.79), t(6)=1.73, p=.135$, but significantly higher levels of individualized consideration compared to intellectual stimulation $(M=2.95 \%, S E=$ $0.20), t(6)=5.87, p=.001$, and idealized influence $(M=1.50 \%, S E=0.34), t(6)=8.62, p=$ .000. Similarly, coaches displayed higher levels of inspirational motivation compared to intellectual stimulation, $t(6)=5.21, p=.002$, and idealized influence, $t(6)=4.86, p=.003$. Finally, coaches exhibited similar levels of intellectual stimulation and idealized influence, $t(6)=$ $3.17, p=.019$.

In sum, the findings suggest that (a) coaches employed similar frequencies of leadership behaviour dimensions across training and competition; (b) coaches most frequently engaged in neutral interactions and silent observation with their athletes (more than $75 \%$ in training and competition); (c) coaches most frequently employed behaviours characterized as individualized consideration, followed by inspirational motivation; (d) the least frequently exhibited TFL 
components were intellectual stimulation followed by idealized influence; and (e) laissez-faire and toxic leadership were the least frequently exhibited behaviours.

\section{Discussion}

Coaches in this study mostly engaged in silent observation and interactive neutral behaviours with their athletes, indicating that more often than not, coaches did not actively display leadership behaviours when intervening with their athletes. It is important to note that observation is indeed an important and necessary behaviour, which allows for reflection on appropriate behavioural interventions (e.g., Erickson, Côté, Hollenstein, \& Deakin, 2011). However, excluding silent observation, coaches displayed a notably high percentage of neutral interactive behaviours in training (47\%) and competition (42.3\%). Although the use of observation, when followed by a leadership behaviour, is an important sequence of behaviours for coaches (Erickson \& Côté, 2015), conventional leadership research (see Turnnidge \& Côté, 2018) might suggest that coach behaviour profiles that feature lower frequencies of neutral interactive behaviours and higher frequencies of TFL behaviours may be optimal for youth engagement. To this end, it would be valuable for future researchers to explore the impact of neutral interactive behaviours on athletes' developmental outcomes.

Despite the high prevalence of neutral interactive behaviours, approximately $20 \%$ of coaches' behaviours in training and in competition were transformational, indicating that youth sport coaches are indeed capable of engaging in a variety of leadership behaviours and naturally display TFL behaviours (Rowold, 2006). When actively engaged in leadership, our findings indicate that coaches displayed higher frequencies of TFL in contrast to transactional, laissezfaire, or toxic behaviours. More specifically, when displaying TFL, there was a tendency for coaches to rely on individualized consideration and inspirational motivation, both of which are 
key contributing factors to athletes' development in sport (Fraser-Thomas \& Côté, 2009; Rowold, 2006; Vella et al., 2013). For example, Fraser-Thomas and Côté (2009) found that coaches' attentiveness to feelings and emotions, and displaying interest in their athletes (i.e., individualized consideration) contributed to perceptions of higher quality relationships with their coaches. In line with this contention, Barling (2014) suggests that behaviours conveying individualized consideration defines the quality of the leader-follower relationship. Moreover, according to Horn (2008) the primary antecedents of coaching behaviours are coaches' expectancies and goals (inspirational motivation), and values and beliefs (idealized influence). Given the prevalence of goal-setting in sport and its emphasis within traditional coach education, it is possible that coaches recognize the value of discussing goals and expectations more than expressing their values and beliefs.

Among TFL behaviours, coaches displayed lower levels of intellectual stimulation and idealized influence. These findings bare similarities to the physical education context, where Morton, Keith, and Beauchamp (2010) found that children perceived intellectual stimulation as the least displayed TFL dimension in the physical educational context. This is notable given that the absence of intellectual stimulation can result in negative effects, such as the potential to undermine youth's motivation and autonomy (Morton et al., 2010; Stenling \& Tafvelin, 2014) by exhibiting a more controlling than autonomy supportive style (Fenton, Duda, Quested, \& Barrett, 2014). Additionally, the limited use of idealized influence is notable since previous studies suggest that youth sport coaches have an important influence on their athletes through their behaviours (Morton et al., 2010; Tucker et al., 2010; Vella et al., 2013).

Although the current methodological approach garnered new and insightful data, limitations must be recognized. First, leadership is complex and multifaceted (Bass \& Riggio, 
2006), therefore, the mere occurrence of a behaviour (e.g., leadership) does not indicate a behaviour achieved its intended purpose (e.g., effective execution). Research efforts pairing observation with other methodologies (e.g., state space grid; Erickson \& Côté, 2015) could provide insight into effective implementation of leadership beyond sheer frequency (e.g., behavioural sequencing). Second, although this study provides a comprehensive picture to describe how leadership behaviours are displayed by youth sport coaches, it fails to capture why coaches engage in varying leadership behaviours. Qualitative interviews with coaches/athletes combined with observational data may help to provide a richer picture of the leadership process.

Overall, this study offers new insight into how coaches display leadership —as defined by the observational instrument used in this study - in their everyday coach-athlete interactions. Generally, the findings suggest that coaches spend the majority of their time exhibiting neutral interactive behaviours. As such there may be opportunities for researchers and practitioners to examine ways to help coaches improve the quantity and quality of their leadership behaviours. For instance, previous studies suggest that TFL behaviours can be developed through training interventions. Accordingly, studies examining how such interventions may influence coaches' behaviours would be beneficial. Although our sample of coaches engaged in positive leadership actions, there are also potential areas of improvement warranting consideration by future leadership workshop developers. That is, future research can draw upon these findings to design more effective interventions. 


\section{References}

Arthur, C. A., Bastardoz, N., \& Eklund, R. (2017). Transformational leadership in sport: Current status and future directions. Current Opinion in Psychology, 16, 78-83.

Barling, J. (2014). The science of leadership: Lessons from research for organizational leaders. New York, NY: Oxford University Press.

Bass, B. M., \& Riggio, R. E. (2006). Transformational leadership (2nd ed.). Mahwah, NJ: Erlbaum.

Erickson, K., \& Côté, J. (2015). The intervention tone of coaches' behaviour: Development of the Assessment of Coaching Tone (ACT) observational coding system. International Journal of Sport Science \& Coaching, 10, 699-716.

Erickson, K., Côté, J., Hollenstein, T., \& Deakin, J. (2011). Examining coach-athlete interactions using state space grids: An observational analysis in competitive youth sport. Psychology of Sport and Exercise, 12, 645-654.

Fraser-Thomas, J., \& Côté, J. (2009). Understanding adolescents' positive and negative developmental experiences in sport. The Sport Psychologist, 23, 2-23.

Fenton, S. A., Duda, J. L., Quested, E., \& Barrett, T. (2014). Coach autonomy support predicts autonomous motivation and daily moderate-to-vigorous physical activity and sedentary time in youth sport participants. Psychology of Sport and Exercise, 15, 453-463.

Horn, T. S. (2008). Coaching effectiveness in the sport domain. In T. Horn (Ed.), Advances in sport psychology (3rd ed.) (pp. 239-268). Champaign, IL: Human Kinetics.

Michie, S., van Stralen, M. M., \& West, R. (2011). The behavior change wheel: A new method for characterizing and designing behavior change interventions. Implementation Science, 6, $42-53$. 
Morton, K. L., Keith, S. E., \& Beauchamp, M. R. (2010). Transformational teaching and physical activity. Journal of Health Psychology, 15, 248-257.

Potrac, P., Brewer, C., Jones, R., Armour, K., \& Hoff, J. (2000). Toward an holistic understanding of the coaching process. Quest, 52, 186-199.

Rowold, J. (2006). Transformational and transactional leadership in martial arts. Journal of Applied Sport Psychology, 18, 312-325.

Stenling, A., \& Tafvelin, S. (2014). Transformational leadership and well-being in sports: The mediating role of need satisfaction. Journal of Applied Sport Psychology, 26, 182-196.

Tucker, S., Turner, N., Barling, J., \& McEvoy, M. (2010). Transformational leadership and childrens' aggression in team settings: A short-term longitudinal study. The Leadership Quarterly, 21, 389-399.

Turnnidge, J., \& Côté, J. (2019). Observing coaches leadership behaviours in sport: The development of the Coach Leadership Assessment System (CLAS). Measurement in Physical Education and Exercise Science. Advance online publication.

Turnnidge, J., \& Côté, J. (2018). Applying transformational leadership theory to coaching research in youth sport: A systematic literature review. International Journal of Sport and Exercise Psychology, 16, 327-342.

Vella, S. A., Oades, L. G., \& Crowe, T. P. (2013). The relationship between coach leadership, the coach-athlete relationship, team success, and the positive developmental experiences of adolescent soccer players. Physical Education and Sport Pedagogy, 18, 549-561.

Vierimaa, M., Turnnidge, J., Evans, M. B., \& Côté, J. (2016). Tools and techniques used in the observation of coach behavior. In P. A. Davis (Ed.), The psychology of effective coaching and management (pp. 111-132). New York, NY: Nova Science Publishers. 
Table 1

The Coach Leadership Assessment System

\begin{tabular}{lll}
$\begin{array}{l}\text { Higher- } \\
\text { Order } \\
\text { Dimension }\end{array}$ & $\begin{array}{l}\text { Lower-Order } \\
\text { Dimension }\end{array}$ & $\begin{array}{l}\text { Example } \\
\text { Behaviour Code }\end{array}$ \\
\hline
\end{tabular}

\begin{tabular}{|c|c|c|}
\hline \multirow[t]{2}{*}{$\begin{array}{l}\text { Idealized } \\
\text { Influence }\end{array}$} & $\begin{array}{l}\text { Discussing/modelling pro-social } \\
\text { values or behaviours }\end{array}$ & $\begin{array}{l}\text { "Alright folks, today we will practice headers. Before we get serious, } \\
\text { here's a quick joke: Why do soccer players do so well in school? They } \\
\text { know how to use their heads!" }\end{array}$ \\
\hline & Showing vulnerability/humility & "Sorry Blair, I'll take responsibility for that, that was my mistake." \\
\hline \multirow{4}{*}{$\begin{array}{l}\text { Inspirational } \\
\text { Motivation }\end{array}$} & Discussing goals/expectations & $\begin{array}{l}\text { "For today's game, I want you to focus on two things: clean passes and } \\
\text { possession." }\end{array}$ \\
\hline & $\begin{array}{l}\text { Expressing confidence in } \\
\text { athlete(s) potential }\end{array}$ & $\begin{array}{l}\text { "Jean, I think you should take the Penalty kick. I know you can do } \\
\text { this." }\end{array}$ \\
\hline & Promoting team concept & "It's important that we work together. There is no 'I' in 'team'." \\
\hline & $\begin{array}{l}\text { Providing } \\
\text { rationales/explanations }\end{array}$ & $\begin{array}{l}\text { "We committed too many turnovers last weekend, so today we will } \\
\text { focus on ball control." }\end{array}$ \\
\hline \multirow{3}{*}{$\begin{array}{l}\text { Intellectual } \\
\text { Stimulation }\end{array}$} & Eliciting athlete input & $\begin{array}{l}\text { "That was a good try Michelle, but what do you think you could have } \\
\text { done differently?" }\end{array}$ \\
\hline & $\begin{array}{l}\text { Sharing decision } \\
\text { making/leadership } \\
\text { responsibilities }\end{array}$ & $\begin{array}{l}\text { "Alright everyone, we have } 15 \text { minutes left in practice. Would you } \\
\text { rather finish with a scrimmage or do you want to practice penalty } \\
\text { kicks?" }\end{array}$ \\
\hline & Emphasizing learning/process & $\begin{array}{l}\text { "Don't worry about it Liz, we learn from our mistakes. Better now than } \\
\text { in a game." }\end{array}$ \\
\hline \multirow{2}{*}{$\begin{array}{l}\text { Individualized } \\
\text { Consideration }\end{array}$} & $\begin{array}{l}\text { Showing interest in athlet } \\
\text { feelings/needs/concerns }\end{array}$ & $\begin{array}{l}\text { "Hey Matthew, how did your exam go today? I remember you said you } \\
\text { were a bit worried about it." }\end{array}$ \\
\hline & $\begin{array}{l}\text { Recognizing athlete } \\
\text { achievements/contributions }\end{array}$ & $\begin{array}{l}\text { "That was excellent, Chantal! That is exactly what I am looking for, } \\
\text { great work!" }\end{array}$ \\
\hline \multirow[b]{2}{*}{ Transactional } & Discussing rewards/penalties & "Every time you turn over the ball, I want to see 10 push-ups." \\
\hline & $\begin{array}{l}\text { Searching for/responding to } \\
\text { deviations from rules or } \\
\text { standards }\end{array}$ & "Ian, stop messing around. Focus please." \\
\hline \multirow{2}{*}{ Neutral } & Silent observation & Coach observes his/her athletes as they attempt a new drill. \\
\hline & Interactive & $\begin{array}{l}\text { "Veronica, today you will play on the left side." or "Luc, take a couple } \\
\text { steps back." }\end{array}$ \\
\hline Laissez-faire & Showing disinterest & $\begin{array}{l}\text { Coach looks at his phone during practice while players wait for } \\
\text { instructions. }\end{array}$ \\
\hline \multirow[t]{2}{*}{ Toxic } & Expressing anger/hostility & $\begin{array}{l}\text { "JORDAN! Get off the field! That was the worst play I've ever seen in } \\
\text { my life!" }\end{array}$ \\
\hline & Modelling anti-social behaviours & "Common ref, that was a terrible call, open your damn eyes for once." \\
\hline
\end{tabular}


Table 2

Percentage Frequency of Higher-order Leadership Dimensions Across Playing Context

\begin{tabular}{|c|c|c|c|c|c|c|c|c|c|}
\hline \multirow[b]{3}{*}{$\begin{array}{l}\text { Playing } \\
\text { Context }\end{array}$} & \multicolumn{7}{|c|}{ Leadership } & \multicolumn{2}{|c|}{ Neutral } \\
\hline & \multicolumn{4}{|c|}{ Transformational Leadership } & \multirow{2}{*}{ Transactional } & \multirow{2}{*}{ Laissez-faire } & \multirow{2}{*}{ Toxic } & \multirow{2}{*}{ Interactive } & \multirow{2}{*}{$\begin{array}{c}\text { Silent } \\
\text { Observation }\end{array}$} \\
\hline & II & IM & IS & IC & & & & & \\
\hline Training & $2.3 \%$ & $7.4 \%$ & $3.9 \%$ & $8.4 \%$ & $2.4 \%$ & $0.2 \%$ & $0.1 \%$ & $47 \%$ & $28.2 \%$ \\
\hline Competition & $0.7 \%$ & $5.9 \%$ & $2.0 \%$ & $10.2 \%$ & $2.3 \%$ & $1.2 \%$ & $0.2 \%$ & $42.3 \%$ & $35.2 \%$ \\
\hline
\end{tabular}

Note: II = Idealized Influence; IM = Inspirational Motivation; IS: Intellectual Stimulation; IC = Individualized Consideration 


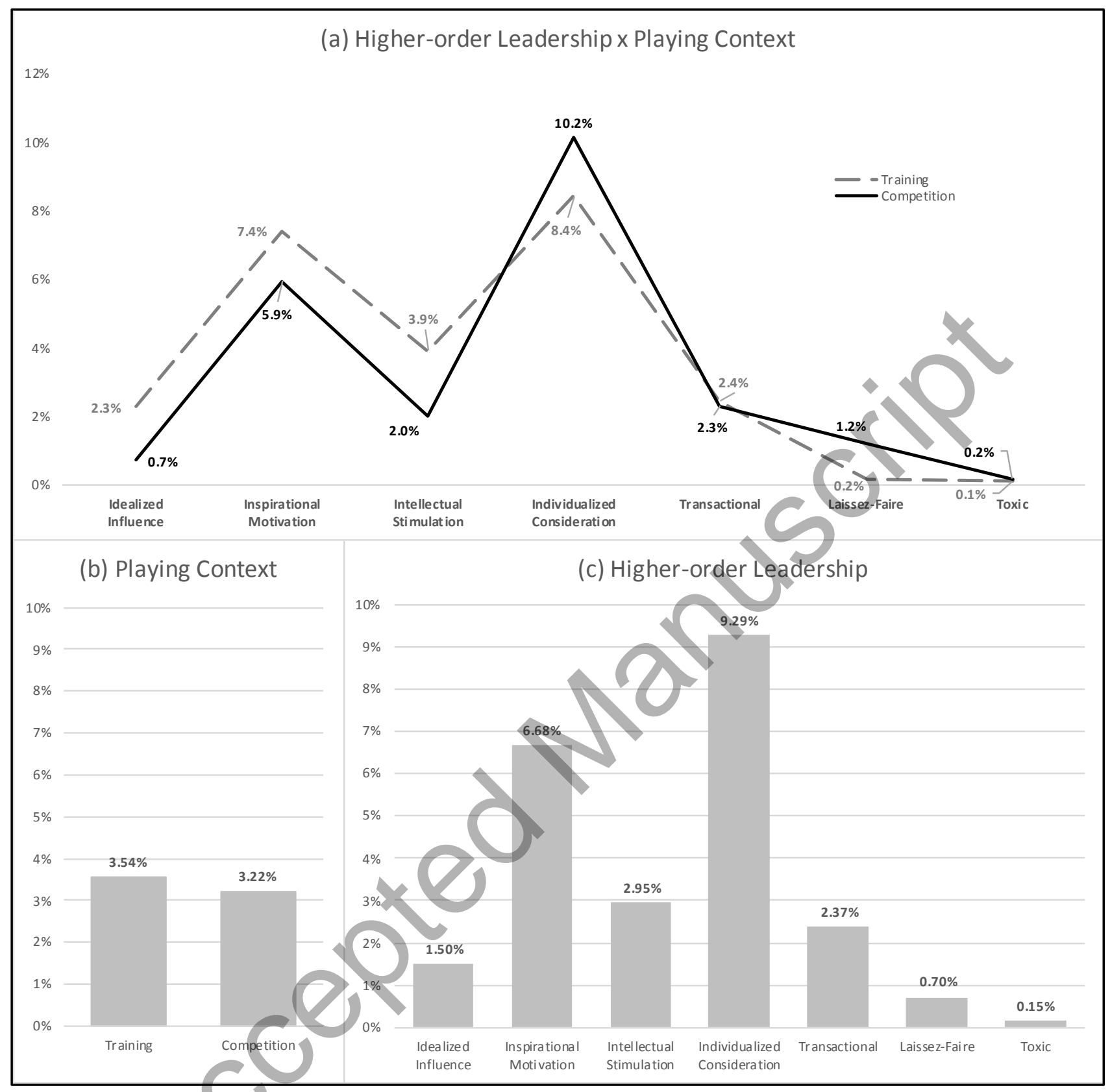

Figure 1. (a) A visual overview displaying the patterns of higher-order leadership dimensions across training and competition. (b) Contrasting leadership across playing contexts. Leadership dimensions were combined to form an average frequency of leadership for each playing context - irrespective of individual dimensions. (c) Contrasting leadership across higher-order dimensions. Playing contexts were combined to isolate the differences across individual dimensions - irrespective of playing contexts. The remaining $76.36 \%$ of behaviours not accounted for in this figure correspond to the neutral dimension (both interactive and silent observation). 